\title{
Sensitivity experiments of impacts of large-scale urbanization in East China on East Asian winter monsoon
}

\author{
CHEN HaiShan ${ }^{1,2 *} \&$ ZHANG Ye $e^{1,2,3}$ \\ ${ }^{1}$ Key Laboratory of Meteorological Disaster of Ministry of Education, Nanjing University of Information Science \& Technology, \\ Nanjing 210044, China; \\ ${ }^{2}$ College of Atmospheric Science, Nanjing University of Information Science \& Technology, Nanjing 210044, China; \\ ${ }^{3}$ Hebei Meteorological Observatory, Shijiazhuang 050021, China
}

Received June 21, 2012; accepted October 26, 2012; published online December 6, 2012

\begin{abstract}
By using the global atmospheric general circulation model CAM4.0 including an urban canopy parameterization scheme, the possible impacts of large-scale urbanization in East China on East Asian winter monsoon was investigated via idealized numerical experiments. Results suggest that large-scale urbanization can cause a significant warming effect in both surface temperature and air temperature near the surface over most areas of East China. Meanwhile, large-scale urbanization also alters the surface energy balance, causing evident increases in net surface long-wave radiation and sensible heat flux as well as intensified surface thermal heating to the atmosphere. Forced by the surface thermal heating anomalies induced by the large-scale urban expansion, East Asian winter monsoon circulation exhibits distinct changes. Overall, the extensive urbanization over East China will weaken East Asian winter monsoon, but intensify winter monsoon in northeast China.
\end{abstract}

large-scale urbanization, East Asian winter monsoon, sensitivity experiment

Citation: Chen H S, Zhang Y. Sensitivity experiments of impacts of large-scale urbanization in East China on East Asian winter monsoon. Chin Sci Bull, 2013, 58: 809-815, doi: 10.1007/s11434-012-5579-z

Land use/land cover change (LULCC) as well as its impacts on climate have received more and more attention during past decades. IPCC AR4 report [1] states that LULCC can affect climate not only at local/regional scales but also at large scales through adjustments in atmospheric general circulation. Studies demonstrated that large-scale LULCC can produce noticeable impacts on the monsoon circulation [2-5]. Several other studies suggest that changes of vegetation coverage can also exert great impacts on climate in China [6-10].

As an extreme case of LULCC, urbanization can affect both the atmospheric circulation and climate at local to regional scales [11-14]. The climatic effect of urbanization attributes to dramatic changes in land surface boundary conditions from natural surfaces to manmade urban areas, which tend to produce the so-called "urban heat island

*Corresponding author (email: haishan@ @uist.edu.cn)
(UHI)" phenomenon as proposed by Howard [15]. In general, UHI is most visible in winter [16], and several recent studies pointed out that the anthropogenic heating plays an important role on the formation of UHI in winter [17-19]. Studies further indicated that the UHI intensity tends to be enhanced under the control of anti-cyclonic circulation [20-25].

Zhou et al. [26] reported a significant urbanization effect in southeast China based on the observational analysis. Previous studies have been focused primarily on the local and regional impacts of urbanization, while impacts of largescale urbanization have received very limited attention. It is generally agreed that urban effects are mainly local and thus have a negligible impact on climate at the global scale. However, the rapid expansion of urban areas in East China is unprecedented in spatial extent and intensity and is expected to modify regional land surface properties dramatically, especially the surface thermal forcing to the atmos- 
phere, at much larger spatial scales than any regions in the world. The question is, will such changes affect the regional general circulation and climate? Answering this scientific question is of great importance with significant societal and economic implications in China. It is well known that China is located in the East Asian monsoon area and the land-sea thermal contrast is a key factor in the formation of the monsoon system. To what extent can the large-scale urbanization over this region alter the land surface thermal forcing, and thus influence the monsoon system? As there are no robust methods to address this question using observations, this study aims to explore the potential impacts of large-scale urbanization on the monsoon system based on idealized numerical sensitivity experiments. As winter usually has stronger UHI than other seasons and the global climate models demonstrate better performance in simulating winter climate $[27,28]$, only the impacts of large-scale urbanization on winter monsoon and climate are investigated in this study.

\section{Model and experiment design}

\subsection{Model}

The global atmospheric general circulation model of the National Center of Atmospheric Research (NCAR) Community Atmosphere Model Version 4.0 (CAM4.0) [29] was used in the current study. CAM4.0 is a component model of the Community Earth System Model (CESM) and can be run in two modes. First, it can be run together with the land surface model (Community Land Model Version 4.0, CLM4.0), the Ocean model (POP2) and the Sea Ice model (CICE4). Second, it can be also run with the land surface model, the sea ice thermal-dynamic model (CICE) and the data ocean model (DOCN) with observational sea surface temperature (SST) and sea ice prescribed as the lower boundary conditions. The second mode is selected in our study.

Currently, a medium-complexity urban canopy model (UCM) [30,31] has been incorporated into CLM4.0. Model parameters of UCM can be categorized into urban spatial parameters, urban morphological parameters and thermal and radiative properties of roofs/walls/roads. The basic features of the urban canopy can be described by 28 model parameters and the relevant processes within the urban canopy are also described by UCM, which make CLM4.0 suitable for the urban related studies. According to population, culture as well as social morphology, the global land has been divided into 33 sub-areas, and the same model parameters are used specifically in each individual urban area. The model has been successfully used in previous studies For example, Oleson [32] used the model to investigate the future responses of the urban and rural climate to different climate change scenarios in the Coupled Model Inter-comparison Project Phase 5 (CMIP5), and Oleson et al.
[33] suggested that the model provides an effective tool to simulate the urban effect.

\subsection{Experimental design}

Two 25-year integration experiments are carried out to explore the possible impacts of large-scale urban expansion in East China on East Asian winter monsoon and the climate in China. The Eulian dynamical core was selected in our experiments and the model was run with T42 horizontal resolution and 26 levels in the vertical direction.

(1) Control run (CTL): Default land cover type and parameters are used. The climatology of monthly SST is prescribed. The model runs from January 1st and continuously is integrated for 25 model years.

(2) Sensitivity experiment (PCT50): Same as CTL run except that the percentage of the urban area in each model grid box in our target area has been increased to $50 \%$ while the default vegetation coverage has been decreased proportionally for each vegetation type. At the same time, the anthropogenic heating has been taken into consideration in this experiment. Figure 1 shows the target domain where the model parameters have been modified.

The last 20-year model results simulated by the two experiments are compared to quantify the possible impacts of large-scale urbanization. All results discussed below represent the differences between PCT50 and CTL (PCT50 minus $(T L)$ in the 20-year averaged meteorological variables in winter.

\section{Results}

\subsection{Control run}

Firstly, simulation results of CTL run are compared with NCEP/NCAR reanalysis to evaluate the model performance

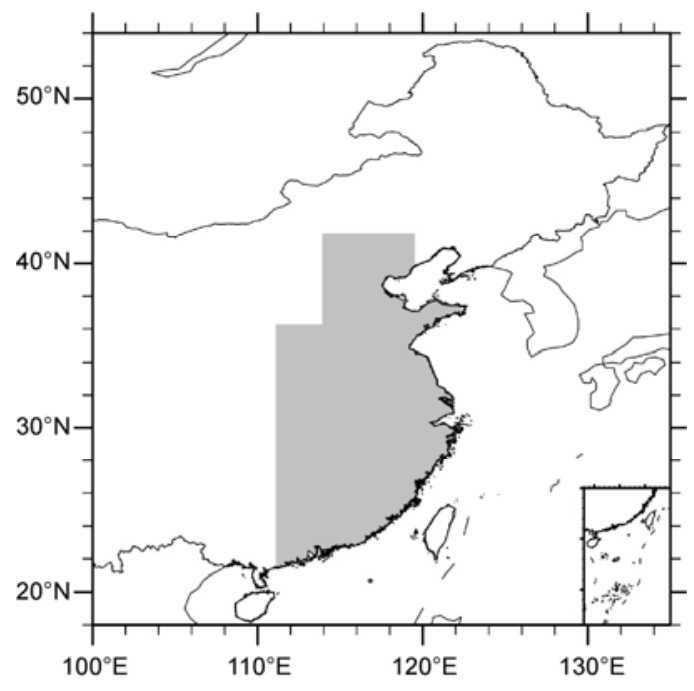

Figure 1 Target domain (shaded area) where the model parameters have been modified in PCT50 run. 
in simulating climate over East Asia. Figure 2(a1)-(a2) shows the $2 \mathrm{~m}$ air temperature. On the whole, the model results agree very well with the reanalysis in the mid-low latitudes over this region, but underestimate the temperatures in the high latitude areas, where cold biases are found in the model simulated $2 \mathrm{~m}$ air temperature. The spatial correlation coefficient between the simulated $2 \mathrm{~m}$ temperature and the reanalysis is 0.993 (statistically significant at the $1 \%$ level) and the root-mean-squared error (RMSE) is $3.067^{\circ} \mathrm{C}$. Figure 2 (b1)-(b2) shows that the model successfully reproduces the observational features of the atmospheric general circulation (wind field and geopotential height) at $850 \mathrm{hPa}$ over East Asia; the spatial correlation coefficient between the simulated $850 \mathrm{hPa}$ geopotential height and the reanalysis is 0.989 (statistically significant at the $1 \%$ level) and the root-mean-square error is $21.91 \mathrm{gpm}$. Overall, CAM3.1 is able to capture the basic features of winter atmospheric general circulation and temperature over East Asia, which provides the basis for the sensitivity study.

\subsection{Sensitivity run}

As the focus of this study is the possible effects of large-scale urbanization on climate and the monsoon circulation over East Asia, the East Asian monsoon area is selected as our study region and possible responses of temperature, surface energy flux, geopotentail height and wind field are discussed in this section.

Previous studies show that albedo is usually lower in urban areas, which causes the land surface to absorb more solar radiation. Meanwhile, urban has larger heat storage capacity than the natural land surface. The anthropogenic heating tends to warm the urban areas significantly, resulting in evident UHI effects and hence completely different thermal states from the natural land surface. Figure 3 shows the difference (PCT50 minus CTL) in surface temperature and air temperature near the surface, which can be used to quantify the possible climatic impacts of large-scale urbanization. Large-scale urbanization increases the surface temperature significantly, especially over those regions with
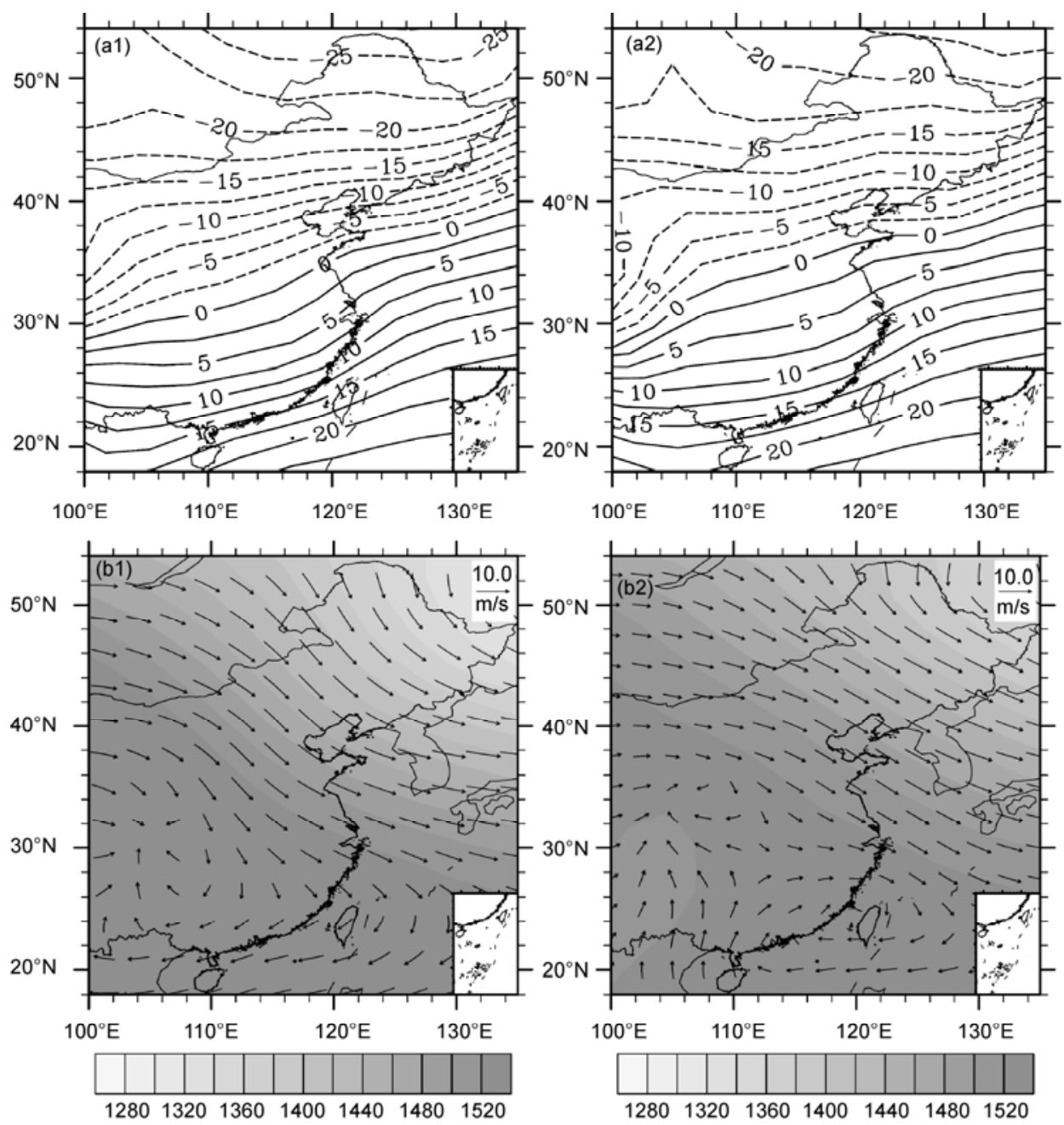

Figure 2 Comparison of simulated results in CTL run and NCEP reanalysis: (a1) and (a2) 2 m air temperature ( ${ }^{\circ} \mathrm{C}$ ); (b1) and (b2) 850 hPa geopotential height and wind field (the shaded area represents the geopotential height in gpm, and the vector is wind field in $\mathrm{m} / \mathrm{s}$ ). " 1 " represents the control run and " 2 " the NCEP reanalysis. 

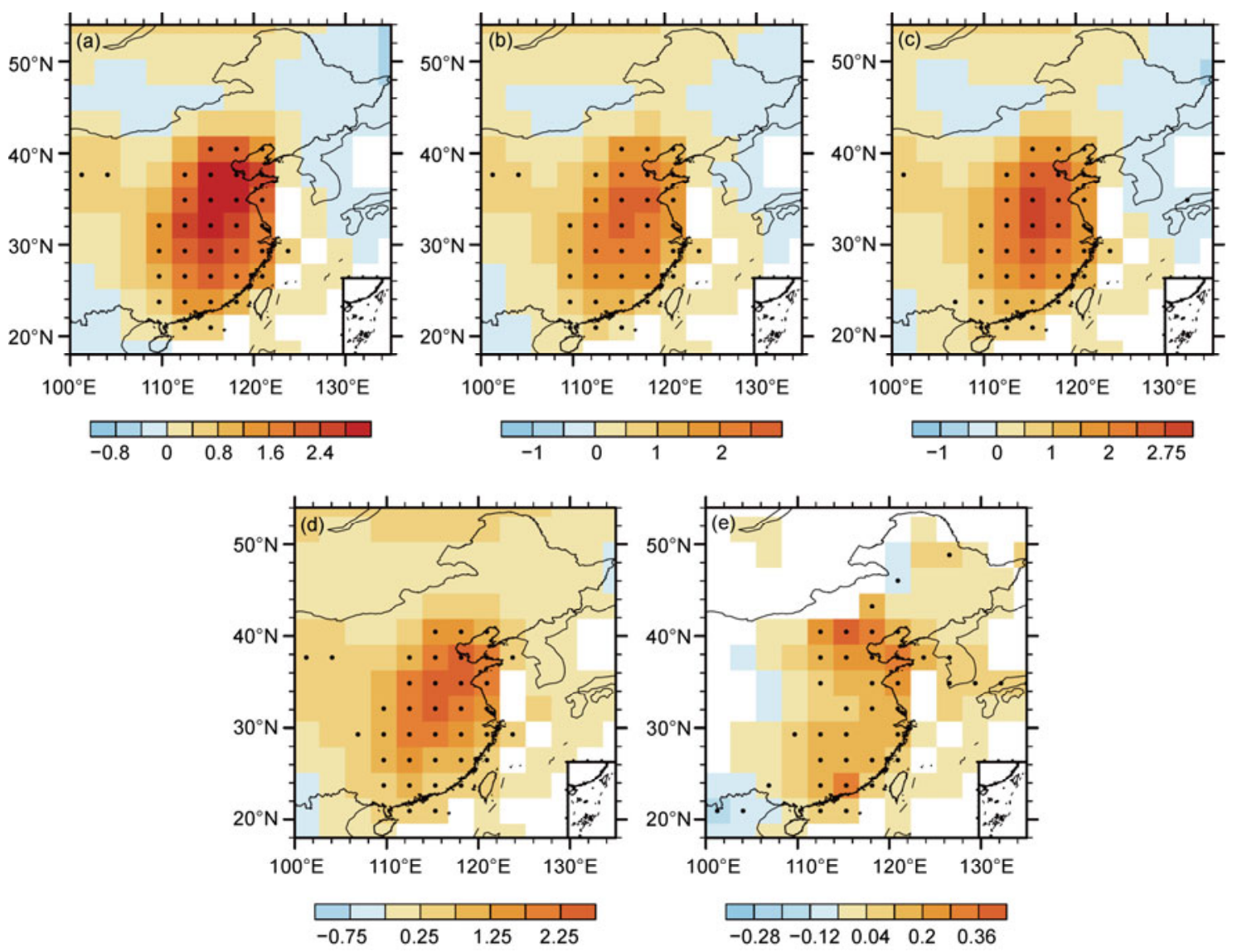

Figure 3 Geographic distribution of differences (PCT50 minus CTL run) in winter (a) surface temperature, (b) $2 \mathrm{~m}$ air temperature, (c) daily minimum $2 \mathrm{~m}$ air temperature, (d) daily maximum $2 \mathrm{~m}$ air temperature and (e) urban heat island intensity in ${ }^{\circ} \mathrm{C}$. The dot-shaded areas indicate that the differences are statistically significant at the $10 \%$ level.

modified land surface parameters in the model, with a warming effect generally above $1^{\circ} \mathrm{C}$ and the maximum of about $3^{\circ} \mathrm{C}$ (Figure 3(a)). It also increases the air temperature near the surface. For example, $2 \mathrm{~m}$ average air temperature, maximum air temperature and minimum air temperature all rise to some extent. It is noted that the spatial patterns of the differences in those variables are similar to those of the surface temperature (Figure 3(b)-(d)). Overall, the increases in daily minimum temperatures over urban areas are evidently larger than those of daily maximum temperatures. To further quantify the UHI effect, the urban-rural temperature difference is estimated and its difference (PCT50 minus CTL) is shown in Figure 3(e). Clearly, winter UHI over East China intensifies significantly under the large-scale urbanization case, and the amplitude of UHI has reached up to $0.36^{\circ} \mathrm{C}$.

Large-scale urbanization alters not only the surface temperature but also the surface energy balance (Figure 4). Compared to the natural land surface, the different components of the surface energy budget as well as the thermal forcing to the atmosphere have been significantly changed under the urbanization case. On the whole, urban expansion tends to increase net short-wave radiation absorbed by the land surface, the net long-wave radiation to the atmosphere (positive toward the atmosphere) and surface sensible heat, but decrease the surface latent heat slightly. Among all the components of the surface energy budget, the changes in sensible heat are most significant while the changes in net long-wave radiation, short-wave radiation and latent heat are relatively small. Pronounced increases in net long-wave radiation and surface sensible heat flux over urban areas are the dominant features. The maximum increase of sensible heat reaches $20 \mathrm{~W} / \mathrm{m}^{2}$, and the maximum increase in net long-wave radiation is also more than $10 \mathrm{~W} / \mathrm{m}^{2}$ (Figure 4(b), (c)). In contrast, no apparent changes are found in the surface net short-wave radiation and latent heat flux. It is noted that the surface heating to the atmosphere enchances significantly with a maximum of $30 \mathrm{~W} / \mathrm{m}^{2}$ (Figure 4(e)). In summary, large-scale urbanization leads to increased surface sensible heat and net long-wave radiation, resulting in enhanced surface thermal heating to the atmosphere. The thermal forcing induced by large-scale urbanization may be responsible for the anomalous general circulation.

Figure 5 show the differences (PCT50 minus CTL) in the geopotential heights at various pressure levels, reflecting the main features of the response of winter atmospheric general circulation to the anomalous thermal forcing induced by large-scale urbanization. Large-scale urbanization evidently 

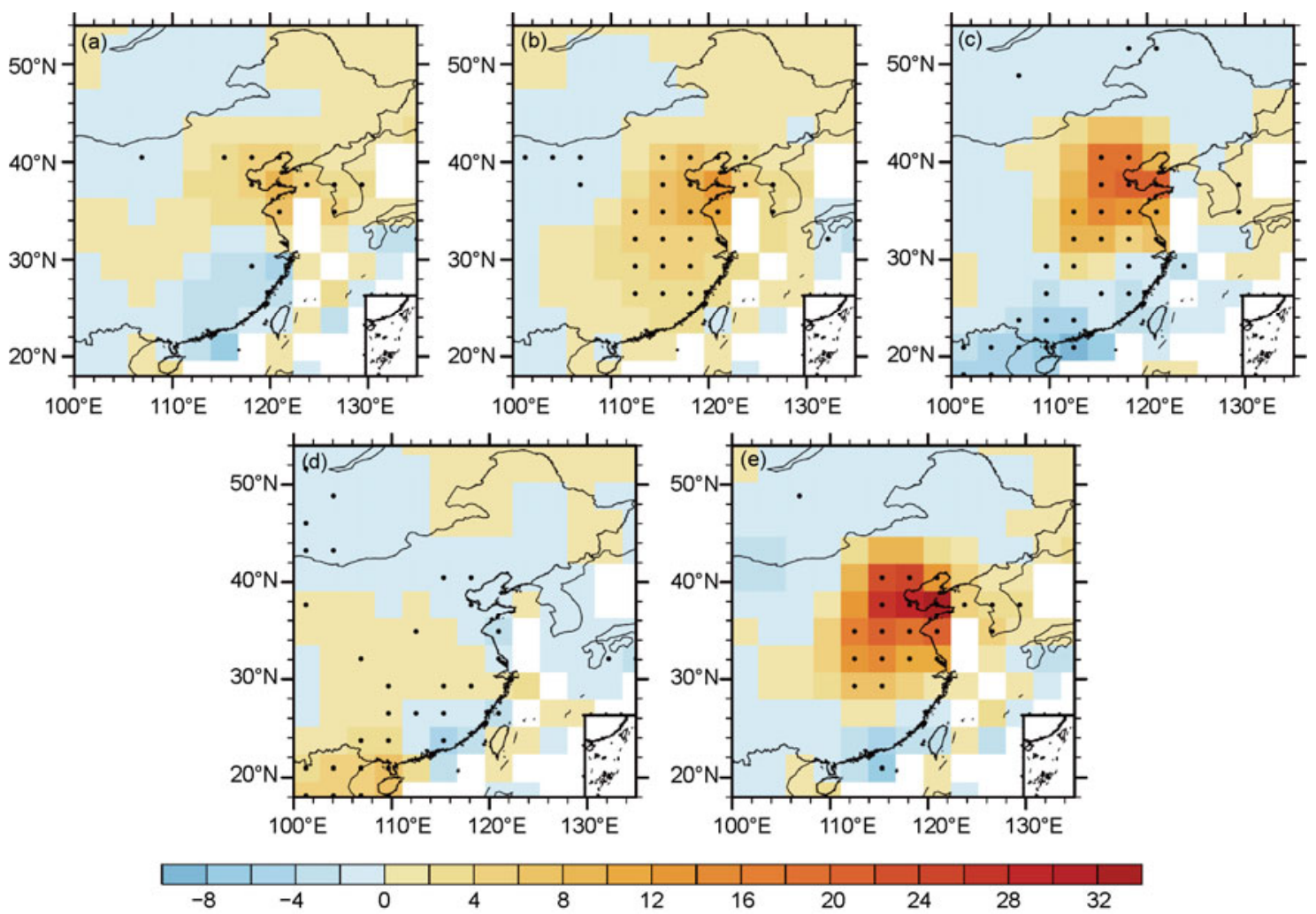

Figure 4 Geographic distribution of simulated differences (PCT50 run minus CTL run) in winter (a) surface net short-wave radiation, (b) net long-wave radiation from the surface to the atmosphere, (c) surface sensible heat flux, (d) latent heat flux and surface heating to the atmosphere in $\mathrm{W} / \mathrm{m}^{2}$. The dot-shaded areas indicate that the differences are statistically significant at the $10 \%$ level.
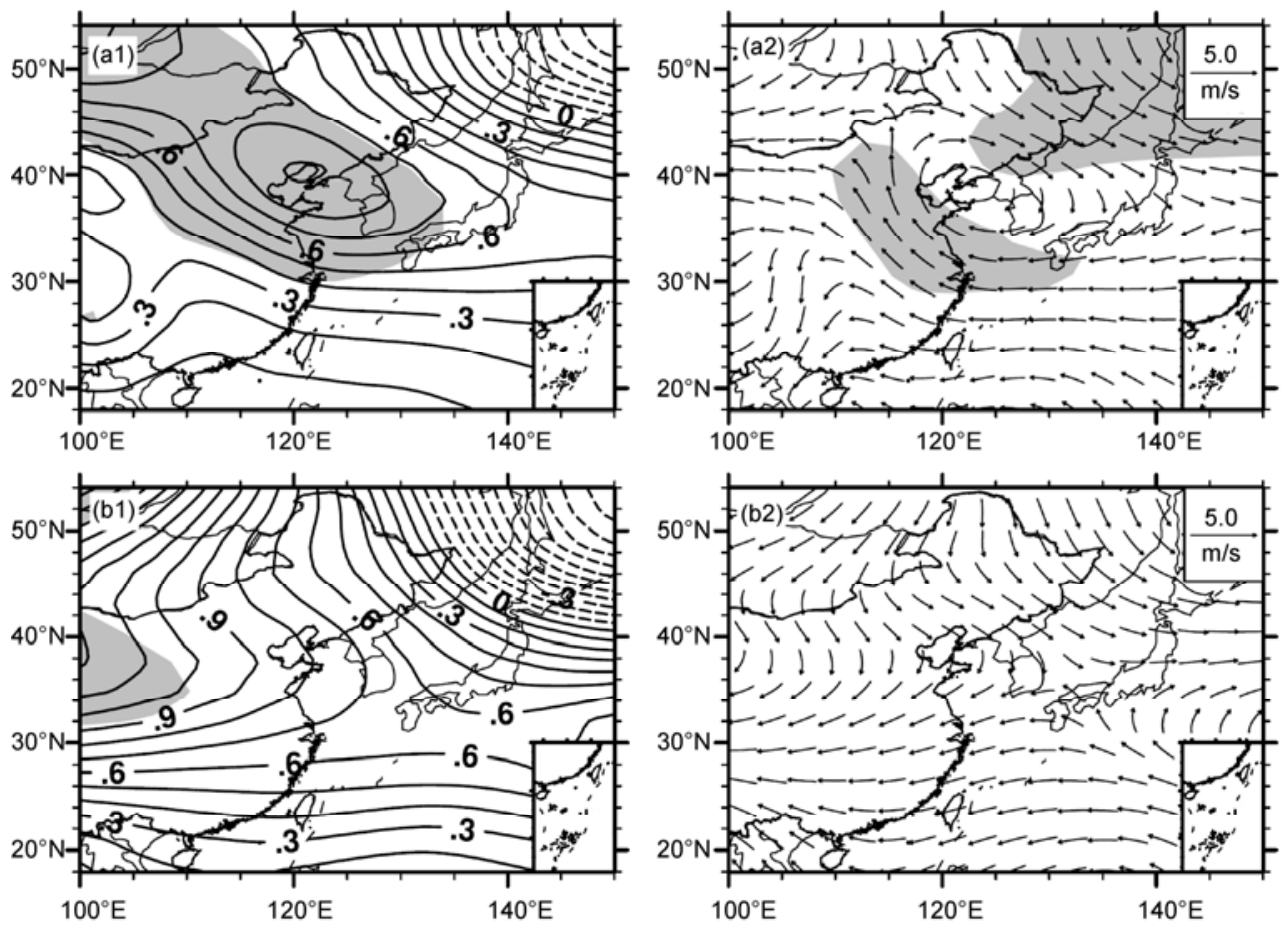

Figure 5 Differences (PCT50 minus CTL) in DJF (a1) $850 \mathrm{hPa}$, (a2) $500 \mathrm{hPa}$ geopotential height in dagpm and (a2) $850 \mathrm{hPa}$, (b2) $500 \mathrm{hPa}$ wind field in $\mathrm{m} / \mathrm{s}$. The shaded areas indicate that the differences are statistically significant at the $1 \%$ level. 
changes the atmospheric circulation over most areas in East Asia. Similar responses of winter geopotental height over East Asia to the surface thermal forcing have also been found in both lower level $(850 \mathrm{hPa})$ and upper level (200 $\mathrm{hPa}$, Figure not given) of the atmosphere. Corresponding to the urban thermal forcing, geopotential heights uplift over most areas of East China. Significant positive anomalies of the geopotential height appear over a belt region extending from the Bohai Bay, across North China, to Mongolia. Notable negative anomalies appear in the downstream area. Similar patterns of the anomalous general circulation are also found at lower $(850 \mathrm{hPa})$, middle $(500 \mathrm{hPa})$ and high (200 hPa, figure not given) levels of the atmosphere. An evidently closed center of the geopotential height anomalies at lower levels is found near the Bohai Bay, which is located to the north-east of the anomalous heating region. It is also noted that the structure of atmospheric response to the anomalous surface thermal forcing has a weak baroclinicity, and significant anomalies of the geopotential height over East Asia become weaker and slanted westward with increasing height. The uplifted geopotential height over most areas of the East Asia can be explained as the direct response to the surface thermal forcing induced by the urbanization, and as a result of the atmospheric adjustment, the geopotential height drops in the downstream area.

To further understand the response of the winter monsoon circulation to the urbanization, the differences of wind fields at various levels between PCT50 and CTL experiments are examined. Corresponding to the spatial patterns of the geopotential height anomalies, lower level wind at $850 \mathrm{hPa}$ has significantly changed in the case of urbanization. Southerly wind anomalies are clearly seen over east China $\left(110^{\circ}-120^{\circ} \mathrm{E}\right)$, with apparent anti-cyclonic (cyclonic) circulation anomalies located in its northeast (southwestern) areas. Accompanied with the southerly wind anomalies over most areas of East China, northerly wind anomalies appear over Northeast China. In contrast, upper level wind anomalies are characterized by the anomalous northerly wind over an extensive region north of $35^{\circ} \mathrm{N}$ but the anomalous easterly wind in southern areas of $35^{\circ} \mathrm{N}$, both of them, however, are relatively weak. In summary, large-scale urbanization over East China tends to weaken the winter monsoon on the whole, but intensify the winter monsoon in Northeast China with clearly enchanced northerly wind. It is also noted that the urban effects on winter atmospheric general circulation mainly happens in the mid to lower levels of the atmosphere.

\section{Conclusion and discussion}

Based on idealized numerical experiments with NCAR CAM4.0, possible impacts of large-scale urbanization in East China on East Asian winter Monsoon are investigated in this study. Results show:
(1) In the large-scale urbanization case, significant warming happens over most urban expansion areas with an increase up to $3^{\circ} \mathrm{C}$ in surface temperature and around $2.5^{\circ} \mathrm{C}$ in surface air temperature. Both winter averaged daily minimum and maximum air temperatures increase significantly over those regions, with a much larger magnitude in the minimum temperature than the maximum temperature. Meanwhile, the average urban-rural temperature difference also rises to by $0.36^{\circ} \mathrm{C}$.

(2) The surface energy balance is altered significantly under the influence of large-scale urbanization. The surface sensible heat flux and net long-wave radiation from the surface to the atmosphere are both increased while increase in the net short-wave radiation and decrease in the latent heat flux are relatively small. Such changes modify the surface energy budget and lead to a thermal heating forcing from the surface to the atmosphere.

(3) Changes in the surface energy budget and the abnormal surface thermal heating can produce evident influence on East Asian winter monsoon. The large-scale urbanization in East China tends to weaken winter monsoon on the whole, but intensify the winter monsoon in the Northeast China accompanied by evidently enchanced northerly wind anomalies. It is also noted that the urban effects on winter atmospheric general circulation mainly happens in the mid to lower levels of the atmosphere.

we explored the possible impacts of large-scale urbanization on the atmospheric general circulation and climate in China and found significant responses of the atmosphere to the urbanization, which can provide some clues for better understanding of the urbanization effect on climate and related physical mechanisms. However, it is difficult to quantify the impacts of realistic urbanization via idealized numerical experiments with an extreme urban expansion scenario. So it is still not clear that to what extent that largescale urbanization will affect large-scale atmospheric general circulation and climate. Therefore, it is necessary to perform further investigation using more realistic urbanization scenarios with high-resolution regional climate models. In addition, we only focus on the impacts due to the changes in surface physical conditions related to urbanization but ignore the likely impacts related to the urban aerosol emission. Both should be considered in the future research in order to better understand the complete impacts of the largescale urbanization.

This work was supported by the National Basic Research Program of China (2010CB428505 and 2011CB952004) and Project Funded by the Priority Academic Program Development of Jiangsu Higher Education Institutions (PAPD). NCEP/NCAR reanalysis were obtained from the NOAACIRES Climate Diagnostics Center through http://www.cdc.noaa.gov/cdc/ reanalysis/reanalysis.shtml. Thanks also go to Dr. Liming Zhou (SUNY, Albany) for his careful review of the language and kindly help in improving the English. We thank anonymous reviewers for their valuable comments and suggestions. 
1 IPCC. Climate Change 2007: The Physical Science Basis//Contribution of Working Group II to the Fourth Assessment Report of the Intergovernmental Panel on Climate Change. Cambridge: Cambridge University Press, 2007

2 Fu C B, Yan H L. An virtual numerical experiment to understand the impacts of recovering natural vegetation on the summer climate and environmental conditions in East Asia. Chin Sci Bull, 2001, 46: 1199-1202

3 Feddema J J, Oleson K W, Bonan G B, et al. The important of landcover change in simulating future climates. Science, 2005, 310: 1674-1678

4 Gao X J, Zhang D F, Chen Z X, et al. Simulation of land effect on climate in China by ReGcm3. Sci China Ser D: Earth Sci, 2007, 50: 620-628

5 Li Q, Xue Y. Simulated impacts of land cover change on summer climate in the Tibetan Plateau. Environ Res Lett, 2010, 5: 015102

6 Notaro M, Gutzler D. Simulated impact of vegetation on climate across the North American monsoon region in CCSM3. 5. Clim Dyn, 2011, 38: 795-814

7 Zheng Y Q, Qian Y F, Miao M Q, et al. The effects of vegetation change on regional climate I: Simulation results (in Chinese). Acta Meteorol Sin, 2002, 60: 1-16

8 Zheng Y Q, Qian Y F, Miao M Q, et al. The effects of vegetation change on regional climate II: Mechanisms (in Chinese). Acta Meteorol Sin, 2002, 60: 17-30

9 Gao X J, Luo Y, Lin W T, et al. Simulation of effects of land use change on climate in China by a regional climate model. Adv Atmos Sci, 2003, 20: 583-592

10 Wu L Y, Zhang J Y, Dong W J. Vegetation effects on mean daily maximum and minimum surface air temperatures over China. Chin Sci Bull, 2011, 56: 900-905

11 Landsberg H E. Man-made climatic changes: Man's activities have altered the climate of urbanized areas and may affect global climate in the future. Science, 1970, 170: 1265-1274

12 Lamptey B L, Barron E J, Pollard D. Impacts of agriculture and urbanization on the climate of the northeastern United States. Glob Planet Change, 2005, 49: 203-221

13 Trusilova K, Jung M, Churkina G, et al. Urbanization Impacts on the Climate in Europe: Numerical Experiments by the PSU-NCAR Mesoscale Model (MM5). J Appl Meteor Climatol, 2008, 47: 14421455

14 Trusilova K, Jung M, Churkina G. On climate impacts of a potential expansion of urban land in Europe. J Appl Meteor Climatol, 2009, 48: 1971-1980

15 Howard L. The Climate of London. London, UK: W. Phillips, 1818

16 Magee N, Curtis J, Wendler G. The urban heat island effect at Fairbanks, Alaska. Theor Appl Climatol, 1999, 64: 9-47

17 Kumar S, Prasad T, Ashidharan N V, et al. Heat island intensities over Brihan Mumbai on a cold winter and hot summer night. Mau- sam, 2001, 52: 703-708

18 Brázdil R, Budiková M. An urban bias in air temperature fluctuations at the Klementinum, Prague, the Czech Republi. Atmos Environ, 1999, 33: 4211-4217

19 Fan H L, David J S. Modeling the impacts of anthropogenic heating on the urban climate of philadelphia: A comparison of implementations in two PBL schemes. Atmos Environ, 2005, 39: 73-84

20 Unwin D J. The synoptic climatology of Birmingham's heat island. Weather, 1980, 35: 43-50

21 Unger J. Heat island intensity with different meteorological conditions in a medium-sized town: Szeged, Hungary. Theor Appl Climatol, 1996, 54: 147-151

22 Shahgedanova M, Burt T P, Davies T D. Some aspects of the threedimensional heat island in Moscow. Int J Climatol, 1997, 17: 1451-1465

23 Tumanov S, Stansion A, Lupu A, et al. Influences of the city of Bucharest on weather and climate parameters. Atmos Environ, 1999, 33 : 4173-4183

24 Morris C J G, Simmonds I. Associations between varying magnitudes of the urban heat island and the synoptic climatology in Melbourne, Australia. Int J Climatol, 2000, 20: 1931-1954

25 Beranová R, Huth R. Long-term changes in the heat island of Prague under different synoptic conditions. Theor Appl Climatol, 2005, 82: 113-118

26 Zhou L M, Dickinson R E, Tian Y, et al. Evidence of a significant urbanization effect on climate in China. Proc Natl Acad Sci USA, 2004, 101: 9540-9544

27 Gao X J, Xu Y, Zhao Z C, et al. On the role of resolution and topography in the simulation of East Asia precipitation. Theor Appl Climatol, 2006, 86:173-185

28 Gao X J, Shi Y, Song R Y, et al. Reduction of future monsoon precipitation over China: Comparison between a high resolution RCM simulation and the driving GCM. Meteorol Atmos Phys, 2008, 100: 73-86

29 Neale R B, Richter J H, Conley A J, et al. Description of the NCAR Community Atmosphere Model (CAM 4.0). Tech Rep NCAR/TN485+STR.National Center for Atmophere Research, Boudlder, Co, 2010

30 Oleson K W, Bonan G B, Feddema J, et al. An urban parameterization for a global climate model. Part I: Formulation and evaluation for two cities. J Appl Meteor Climatol, 2008, 47: 1038-1060

31 Oleson K W, Bonan G B, Feddema J, et al. An urban parameterization for a global climate model. Part II: Sensitivity to input parameters and the simulated urban heat island in offline simulations. J Appl Meteor Climatol, 2008, 47: 1061-1076

32 Oleson K W. Contrasts between urban and rural climate in CCSM4 CMIP5 climate change scenarios. J Clim, 2012, 25: 1390-1412

33 Oleson K W, Bonan G B, Feddema J. Effects of white roofs on urban temperature in a global climate model. Geophys Res Lett, 2010, 37: L03701

Open Access This article is distributed under the terms of the Creative Commons Attribution License which permits any use, distribution, and reproduction in any medium, provided the original author(s) and source are credited. 